\title{
Authors' Reply to McMahon et al. Comment on: "Anthropometric and Physical Qualities of Elite Male Youth Rugby League Players"
}

\author{
${\text { Kevin } \text { Till }^{1} \cdot \text { Sean Scantlebury }}^{1} \cdot$ Ben Jones $^{1}$
}

Published online: 17 August 2017

(c) The Author(s) 2017. This article is an open access publication

\section{Dear Editor,}

We would like to thank McMahon et al. [1] for their kind and constructive comments on our recent review article [2]. After reading the comments by McMahon et al. [1], we fully acknowledge that we did not discuss the validity of the methods used to derive countermovement jump (CMJ) height within our review. Therefore, the comments by McMahon et al. [1] do supplement the review article with important information for research and practice within rugby league and other sports.

The valid comments provided by McMahon et al. [1] relating to the CMJ height are not the only methodological considerations that should be applied to our review paper [2]. For example, aerobic capacity is an estimate of maximum oxygen uptake (i.e. estimated $\mathrm{VO}_{2 \max }$ ) predicted from field-based tests [e.g. multistage fitness test (MSFT) and Yo-Yo intermittent recovery test level 1 (Yo-Yo)]. Prediction equations derived from these field-based tests to estimate $\mathrm{VO}_{2 \max }$ inherently induce a degree of error [3]. Furthermore, due to advances in knowledge and methodologies within research, it is also important to note the changes in testing batteries used, and how data are reported. For example, recently Yo-Yo test data have been reported as distance covered [4,5], as opposed to estimated $\mathrm{VO}_{2 \max }$ in earlier studies [6]. This is represented in Table 2 in Till et al. [2], which presents four types of aerobic capacity data (i.e. MSFT estimated $\mathrm{VO}_{2 \max }$, MSFT level, Yo-Yo estimated $\mathrm{VO}_{2 \max }$ and Yo-Yo distance) based on recent

Kevin Till

K.Till@leedsbeckett.ac.uk

Leeds Beckett University, City Campus, Leeds LS1 3HE, UK changes within the literature. These methodological considerations highlight the importance of critically evaluating the current literature by researchers and practitioners alike.

Regarding the CMJ specifically, it now appears more common for researchers in the field to use a force platform for the collection of CMJ height (e.g. Darrall-Jones et al. [5], Ireton et al. [7] and Roe et al. [8]) as opposed to the methods (i.e. Takei Vertical Jump Meter, Just Jump System, and Yardstick Jump Testing System) highlighted by McMahon et al. [1]. This suggests that within the assessment of physical qualities, researchers are applying scientifically valid measurements where possible (e.g. equipment availability) to increase understanding of performance, which is likely due to the increased availability of scientific equipment. Regardless of the equipment used within studies, we recommend that when both researchers and practitioners apply data from the literature to their cohort, they should establish their own population-specific typical error and smallest worthwhile change reliability data to determine meaningful changes [9].

\section{Compliance with Ethical Standards}

Funding No sources of funding were used to assist in the preparation of this letter.

Conflict of interest Kevin Till, Sean Scantlebury and Ben Jones declare that they have no conflicts of interest relevant to the content of this letter.

Open Access This article is distributed under the terms of the Creative Commons Attribution 4.0 International License (http:// creativecommons.org/licenses/by/4.0/), which permits unrestricted use, distribution, and reproduction in any medium, provided you give appropriate credit to the original author(s) and the source, provide a link to the Creative Commons license, and indicate if changes were made. 


\section{References}

1. McMahon JJ, Jones PA, Comfort P. Comment on: "Anthropometric and physical qualities of elite male youth rugby league players". Sports Med. 2017. doi:10.1007/s40279-017-0771-6.

2. Till K, Scantlebury S, Jones B. Anthropometric and physical qualities of elite male youth rugby league players. Sports Med. 2017. doi:10.1007/s40279-017-0745-8.

3. Bansgbo J, Iaia FM, Krustrup P. The Yo-Yo intermittent recovery test: a useful tool for evaluation of physical performance in intermittent sports. Sports Med. 2008;38(1):37-51.

4. Till K, Jones B, Darrall-Jones J, et al. Longitudinal development of anthropometric and physical characteristics within academy rugby league players. J Strength Cond Res. 2015;29(6):1713-22.

5. Darrall-Jones J, Jones B, Till K. Anthropometric and physical profiles of English academy rugby union players. J Strength Cond Res. 2015;29(8):2086-96.
6. Till K, Tester E, Jones B, et al. Anthropometric and physical characteristics of English academy rugby league players. J Strength Cond Res. 2014;28(2):319-27.

7. Ireton M, Till K, Weaving D, et al. Differences in the movement skills and physical qualities of elite senior and academy rugby league players. J Strength Cond Res. 2017. doi:10.1519/JSC. 0000000000002016.

8. Roe G, Darrall-Jones J, Till K, et al. Preseason changes in markers of lower body fatigue and performance in young professional rugby union players. Eur J Sports Sci. 2016;16(8):981-8.

9. Roe G, Darrall-Jones J, Till K, et al. Between-day reliability and sensitivity of common fatigue measures in rugby players. Int $\mathbf{J}$ Sports Physiol Perform. 2016;11(5):581-6. 